\title{
Três obras para o Conjunto de Percussão da UFBA, o primeiro
}

\section{grupo de percussão do Brasil}

\author{
Aquim Almeida, Cecilia Tamplenizza
}

\author{
Universidade Federal da Bahia | Brasil
}

\begin{abstract}
Resumo: O século XX foi um período de muita experimentação para a música percussiva. Foram criados os primeiros grupos de percussão, com composições autorais próprias. Nelas se observa a introdução de elementos musicais que inovaram a percussão clássica. Com a adoção de diversos instrumentos surgiram novas possibilidades sonoras e a compreensão do som foi ampliada. Depois de uma breve introdução sobre as inovações que o século XX reservou para a cena percussiva e um breve panorama sobre o fenômeno do grupo de percussão, esse artigo aborda o primeiro grupo brasileiro de percussão, o Conjunto de Percussão da UFBA, seus compositores baianos Jamary Oliveira (1944-2020), Lindembergue Cardoso (1939-1989) e Fernando Cerqueira (1941-) e três de suas obras. Obras que trazem muitas inovaçôes para o repertório brasileiro percussivo atual.
\end{abstract}

Palavras-chave: Performance, Grupo de percussão, Música escrita ocidental, Compositores baianos.

\begin{abstract}
The 20th century was a period of experimentation for percussive music. The first percussion groups were created with their own authorial composition. It is possible to observe the introduction of musical elements that innovated classical percussion. With the adoption of various instruments, new sound possibilities arose, and the understanding of sound was expanded. After a brief introduction about the innovations that the 20th century reserved for the percussion scene and a brief overview of the percussion group phenomenon, this article addresses the first Brazilian percussion group, the UFBA Percussion Ensemble, its baianos composers Jamary Oliveira (1944-2020), Lindembergue Cardoso (1939-1989) and Fernando Cerqueira (1941-) and three of his works. Works that bring many innovations to the current Brazilian percussive repertoire.
\end{abstract}

Keywords: Performance, Percussion Group, Western written music, Bahiano composers. 


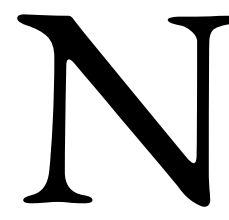

esse artigo introduzimos o surgimento dos grupos de percussão, bem como os primeiros compositores e obras escritas para esses conjuntos. Refletimos sobre as inovações musicais que esses ensembles propiciaram na percussão contemporânea ${ }^{1}$, através da leitura e apresentação de três obras compostas para o Conjunto de Percussão da UFBA por compositores baianos: Ritual e Transe (1964) de Jamary Oliveira, Caricaturas (1968) de Lindembergue Cardoso e Expressóes Cibernéticas (1985) de Fernando Cerqueira. Para pensar sobre essas novidades, é preciso primeiro contextualizar seu surgimento e definir alguns conceitos que norteiam esse artigo. Refletir sobre o panorama histórico e cultural em que aconteceram essas inovações musicais nos faz compreender melhor o crescente interesse dos compositores com esse repertório e as novas propostas musicais ali contidas.

Entre os séculos XIX e XX houve um processo de expansão do conceito de música escrita ocidental que afetou a música para instrumento de percussão e o papel desse naipe na orquestra sinfônica. Assistimos, assim, à expansão das possibilidades sonoras, com a criação e adoção de instrumentos que não eram usuais na música escrita ocidental escrita para percussão. Por exemplo, são introduzidos instrumentos de países não ocidentais, objetos comuns usados como instrumentos musicais e além da voz que começa a ser explorada como instrumento de percussão. Sons do contexto cotidiano e outros que antes eram considerados ruídos são apresentados ao público nas salas de concerto.

Entre os pesquisadores da área, existe certo consenso sobre o crescente interesse dos compositores com os instrumentos de percussão a partir do fim do século XIX e começo do século XX. Segundo Tullio (2014, p. 19), antes dos anos de 1930, "a percussão era tratada basicamente como acompanhamento ou reforço rítmico, ou como efeito timbrístico dentro da orquestra”. Para Navas (2016, p. 18), a partir do século XX: “a percussão passa a ter um lugar importante, deixando de ser apenas apoio a outros instrumentos e tornando-se independente. 'A child of the twentieth century ${ }^{2}$ 'é como o percussionista Steven Schick se refere à percussão do século XX em diante.”

Existem diferentes razões que permitiram o surgimento desse renovado interesse com a percussão, algumas musicais, tais como "o surgimento do dodecafonismo e novas escalas, o

\footnotetext{
1 “Entendendo a "percussão contemporânea” como aquela que saiu do fundo das orquestras sinfônicas, no início do século XX, e veio para a boca de cena, tratada como um instrumento solista” (TULLIO, 2014, p. 19).

${ }^{2}$ Uma criança do século vinte (Tradução nossa).
} 
Movimento Futurista, a experimentação sonora com musique concrète, a aleatoriedade, entre outras” (NAVAS, 2016, p. 18); “as combinações ritmo/timbre, som/efeitos, além da atenção voltada para os timbres sonoros e às técnicas dos instrumentos extra europeus do mundo inteiro ${ }^{3 "}$ (FACCHIN, 2014, p. 29, tradução nossa). Outras razões extra musicais, como a Segunda Revolução Industrial, “a influência da industrialização e da modernização das cidades” (TULLIO, 2014, p. 21), as guerras mundiais, a consequente transformação do pensamento sobre humanidade, uma extensa reflexão filosófica e sociológica sobre o homem contemporâneo e o papel das artes puderam ser notadas. As certezas do otimismo positivista foram suplantadas pelas atrocidades das guerras mundiais, com um forte impacto na psicologia humana, colocando em dúvida o sentido da humanidade.

O otimismo remanescente do culto ao progresso que acompanhava a aurora de um novo século ali era largamente carregado de ameaças e de más surpresas. Inspiravam-se, na realidade, em uma visão de história dos decênios precedentes cheia de conotações negativas. É a Primeira Guerra Mundial, catástrofe que ultrapassa em horror todos esses prognósticos angustiantes, e o surgimento progressivo de um cronônimo novo e concorrente, Belle époque, que contribui mais ainda para comprometer a carreira e a lembrança do fin de siècle $e^{4}$. (CHARLE, 2018, p. 259).

Assim como outros atores sociais, os músicos sofreram muitas perdas nesse momento. Tullio (2014, p. 21) lembra que o compositor Edgar Varèse, por exemplo, francês radicado em Nova Iorque desde 1916, perdeu toda a produção da juventude em um incêndio durante a Primeira Guerra Mundial. Nesse longo período de perda e insegurança pelo futuro, - as guerras mundiais não foram as primeiras guerras que a Europa viveu, mas foram as mais violentas e assinalaram o colapso da civilização (ocidental) do século XIX (HOBSBAWM, 1994, p. 14) - o desejo de expressar e viver o presente se tornou central. O próprio conceito de modernidade é composto pelo advérbio latim modo, que significa agora, neste momento. "Uma condição que”, sugere o antropólogo Remotti (2014, cap. 4), "muda incessantemente, assim como cada instante do presente sucede o outro" (Tradução nossa).

\footnotetext{
3 "Combinazioni ritmo/timbro, suono/effetti, oltre che per la particolare attenzione rivolta alle timbriche sonore e alle tecniche degli strumenti extraeuropei di tutto il mondo”.

4 'Fin de siècle', em francês, significa 'fim do século'. Foi um movimento cultural difundido especialmente na Europa Central, entre o 1880 e o começo da Primeira Guerra Mundial.

5 "Una condizione dunque che muta incessantemente, esattamente come si susseguono gli istanti del presente".
} 
Em uma época de grandes contrastes, a industrialização e modernização revolucionaram a vida nas cidades e foram transformando o gosto e a percepção humana. Segundo Klingender (1972), a arte produzida na primeira metade do século XX foi fortemente influenciada pelas transformaçóes socioeconômicas e políticas proporcionadas pelas novas máquinas e pelo rápido crescimento das cidades industrializadas. Um processo em que se estabeleceram novas relaçôes e valores, e em que as noçôes do tempo e do espaço aceleraram abrupta e rapidamente.

Além dessas transformações psicológicas e sociais, durante a Segunda Revolução Industrial, foram inventadas e desenvolvidas novas tecnologias, materiais sintéticos e metais, novas fontes de energia, que ofereceram aos artistas a possibilidade de inovar técnicas, instrumentos e que levaram ao surgimento de novas funções e profissões (KLINGENDER, 1972; SCHAFER, 2001). Falando de uma maneira mais específica sobre música, Schafer (2001, p. 107) analisa o impacto da sociedade pósindustrial na audição humana. A revolução industrial introduziu muitos novos sons, influenciando as paisagens sonoras da época até a atualidade. Esse momento de grande mudança e de desejo de distanciamento do passado, é absorvido pelas artes como um período de experimentação e de transformação de paradigmas.

Outra transformação que teve um impulso fundamental nesse período foi a mobilidade. A possibilidade, cada vez mais rápida e acessível, de viajar motivou muitos compositores e músicos dessa época a conhecer países distantes, com suas diferentes maneiras de entender e produzir música e instrumentos musicais, não só por meio de gravações ou em Exposiçôes Mundiais que influenciaram compositores como Claude Debussy e Nikolaj Andreevič Rimskij-Korsakov, mas por experiência direta com conhecimento do uso dos instrumentos em cada país. Nesse sentido, o compositor Béla Bartók, com suas viagens pelo Leste da Europa foi um precursor desse interesse pelo campo de pesquisa.

Ao longo do século XX e início do século XXI, a possibilidade de viajar tomou significativa proporção para a música escrita ocidental, afirma o percussionista Guido Facchin (2014, p. 30): “O interesse por ruído, a utilização do ritmo e a atenção pela música extra europeia, e precisamente através desta música que chegamos à evolução da nossa prática musical”“6 (Tradução nossa).

\footnotetext{
6 "L'interesse per il rumore, l'utilità del ritmo e l'attenzione per le musiche extraeuropee, e proprio attraverso tali musiche si è arrivati all'evoluzione della nostra pratica musicale”.
} 
Nesse contexto de transformações e encontros, a noção de música escrita ocidental é repensada, novos instrumentos são criados, antigos instrumentos são reposicionados em diversos ambientes e são adotados com funçôes diferentes. Sons, que até então eram considerados ruídos e outros jamais ouvidos, são incorporados às composições. Todos esses elementos, veremos, transportaram a percussão para o centro da experimentação musical.

\title{
1 - Movimentos, obras e outras influências da primeira metade do século XX
}

Citaremos agora alguns movimentos artísticos, obras e compositores que influenciaram, de maneira decisiva, o repertório contemporâneo de percussão. Começamos pelo Futurismo, um movimento artístico e literário, iniciado of icialmente pelo poeta italiano Filippo Tommaso Marinetti (1876-1942), com a publicação do “Manifesto Futurista” de 1908. Segundo Vanlamdimgham (1972, p. 71; apud Tullio e Sulpicio (2016, p. 2):

\begin{abstract}
Este movimento rejeitava o moralismo e o passado e intencionava estabelecer uma arte para a sociedade industrial, tendo sido adaptado para a música pelo compositor Francesco Balilla Pratella (1880-1955) e por Luigi Russolo (1885-1947), um pintor que se voltou para a música e tornou-se um de seus principais representantes. O Movimento espalhou-se rapidamente e após a Primeira Guerra Mundial, já estava presente em muitos países (FULTON, 1999, p. 3). Em 1913, Russolo criou e publicou o manifesto L'Arte dei Rumori, estabelecendo algumas leis que conduziriam o Movimento. O documento expressava a ideia de que o som musical era muito limitado e que o futuro da música repousava sobre a organização dos sons. Seis famílias de ruídos, que constituíam a orquestra futurista, foram organizadas por Russolo, sendo a quinta família dedicada inteiramente aos instrumentos de percussão: "ruídos obtidos com percussão sobre metais, madeiras, peles, pedras, terracotas, etc." (op. cit., p. 4). Desta forma, "suprindo os instrumentos melódicos e conferindo monopólio à percussão, o Futurismo enfatizou a importância do ritmo e revelou as possibilidades timbrísticas próprias da percussão".
\end{abstract}

Além de reforçar a importância do ritmo e do uso da percussão, o Futurismo abre caminho para a introdução de objetos do cotidiano utilizados como instrumentos musicais. A primeira categoria da orquestra futurista é composta por "Roncos, Trovoadas, Explosóes, Ruídos de água caindo, Ruídos de objetos que caem na água, Ruídos”7 (RUSSOLO, 1916, p. 15). A voz também começa a ser explorada por suas diversas capacidades sonoras, por suas diferentes formas de emissão

\footnotetext{
7 "Rombi, Tuoni, Scoppia, Scrosci, Tonfi, Boati”.
} 
ou até mesmo por sua capacidade de produzir ruídos e versos. As categorias números dois, três e seis de Luigi Russolo (1916, p.15) evidenciam essas possibilidades: “2. Assobios, Roncos humanos, Bufadas; 3. Sussurros, Murmúrios, Resmungos, Grunhidos, Gargarejos; 6. Vozes animais e humanas: Gritos, Gritos Estridente, Gemidos, Urro, Uivos, Risos, Estertor, Soluços”» (Tradução nossa).

Essas novidades estão diretamente ligadas ao pensamento de vanguarda e a ideia, expressada por Russolo (1916, p. 14-15, tradução nossa), de: “entoar e regular harmonicamente e ritmicamente essa grande variedade de ruídos”. Pois, continua Russolo: “cada ruído possui uma entonação, talvez também um acorde que predomina no conjunto de suas vibrações irregulares [...] Os desenhos rítmicos dos ruídos são infinitos. Sempre existe, como para o tom, um ritmo predominante”10

Segundo Barreto (2009, p. 7):

Fez parte deste pensamento de vanguarda a superação da tonalidade, propiciar um enriquecimento tímbrico a partir de sons-ruído transformando-os em tons (Varése) [sic], compreender os ruídos em conjunção com a idéia de timbre (Shaeffer) [sic]. Grande parte dos instrumentos de percussão é de altura indeterminada, portanto inexprimíveis pelas notas da gama temperada. Uma grande variedade timbrística é o principal recurso estratégico do uso da percussão no discurso da música contemporânea.

As obras do Movimento Futurista e da Machine Music, nome que o grupo utilizou a partir dos anos de 1920, "proporcionaram aos compositores uma grande abertura de ideias em relação ao uso da percussão" (TULLIO, 2014, p. 20).

Nesse período, a obra do compositor Igor Stravinsky também foi central no desenvolvimento dos estudos sobre percussão. A crise econômica causada pela Primeira Guerra Mundial levou as orquestras a falência e Stravinsky idealizou um pequeno grupo de música de câmara, fácil de transportar e de custear para realizar turnês pela Europa, com o qual executou inúmeros concertos.

\footnotetext{
Mediante essa iniciativa, o percussionista que fez a estreia da obra $A$ História do Soldado lançou na música contemporânea a versatilidade de executar vários instrumentos de percussão, ao que chamamos de percussão múltipla (multiple percussion) [...] A História do Soldado, que termina com um solo de percussão, teve sua primeira execução em 28 de setembro de 1918 no Theatre Municipal de Lausanne 'Suiça, com a regência do maestro, amigo de Stravinsky, Ernest Ansermet. (TULLIO, 2014, p. 20).
}

\footnotetext{
8 "2. Fischi, Sibili, Sbuffi; 3. Bisbigli, Mormorii, Borbottii, Brusii, Gorgogli; 6. Voci di animali e di uomini: Gridi, Strilli, Gemiti, Urla, Ululati, Risate, Rantolii, Singhiozzi”.

9 "Intonare e regolare armonicamente e ritmicamente questi svariatissimi rumori".

10 "Ogni rumore ha un tono, talora anche un accordo che predomina nell'insieme delle sue vibrazioni irregolari [...] I movimenti ritmici di un rumore sono infiniti. Esiste sempre, como per il tono, un ritmo predominante”.
} 
Cabe lembrar que até então não era usual, em uma orquestra, o espaço para um solo de percussão. A partir desse momento, cresce o interesse por esse tipo de acontecimento. No repertório de Stravinsky é também experimentada a união de percussões típicas dos grupos e concertos da tradição musical ocidental com instrumentos percussivos populares ou característicos de diversas regiões e países.

Algumas obras compostas nos anos de 1920 e 1930 hoje são consideradas referências para o repertório de percussão contemporânea. Entre elas, lembramos Ballet Mécanique ${ }^{11}$ (1924) de George Antheil (1924), Le Pas d'Acier (1927) de Sergei Prokofiev ${ }^{12}$ e Ionisation (1930) Edgard Varèse, do qual falaremos em detalhe mais adiante. Além disso, esse compositor foi um dos primeiros a compor obras para grupo de percussão, que, lembra Tullio (2014, p.20), "criou instrumentos de percussão para adquirir sons nunca antes ouvidos, e a barreira entre som e ruído deixou de existir em seu trabalho".

\section{2 - Música para grupo de percussão}

Na tradição musical escrita ocidental, a partir do final dos anos de 1930 e os anos 1940, surgem as primeiras obras para grupo de percussão (exemplificaremos mais adiante), nas quais os compositores, influenciados pelo Futurismo, exploraram uma variedade de recursos musicais novos. Apesar de existirem desde a antiguidade, os conjuntos ou ensembles ${ }^{13}$ de percussão foram significativamente explorados nesse período, mas ainda não existiam grupos estáveis assim como os conhecemos hoje. Nos Estados Unidos os primeiros grupos começam a ser organizados a partir do final dos anos 30 em ambiente universitário. Paul Price e John Cage foram dois músicos importantes nesse processo. Nos anos em que foi professor da Cornish School, entre 1937 e 1939, Cage organizou um grupo de percussão de estudantes que realizou turnês na costa noroeste dos Estados Unidos

\footnotetext{
${ }^{11}$ Existem diversas versóes dessa peça, onde o número de pianos varia entre 2 e 8 . Originalmente foi escrita por para 8 pianos, 4 xilofones, bells, gongos, bigornas, tambores e dois motores de avião (HASHIMOTO, 2003, p. 32). Uma performance está disponível nesse link: https://www.youtube.com/watch?v=SWlQUlzh80w. Outra performance: https://www.youtube.com/watch?v=FR9Qg7YVHaU. Sugerimos também esta performance que foi feita em sincronia com o filme de 1924 - https://www.youtube.com/watch?v=oWa2iy-0TEQ. Acesso em: 20 jan. 2021.

${ }^{12}$ Para um estudo mais completo das obras e compositores que, nesse período, valorizaram o uso da percussão no conjunto instrumental, sugerimos a leitura de Tullio (2014).

${ }^{13}$ Ensemble é uma palavra francesa que significa 'conjunto', no contexto musical contemporâneo é utilizada para se referir a um grupo de músicos que tocam juntos.
} 
(HASIMOTO, 2003, p. 49). Segundo Price (apud HASHIMOTO, 2003, p. 49), nesse período havia "uma boa quantidade de música escrita entre 1930 e 1939, mas não foram tocadas porque não havia muitas pessoas interessadas. Houve amadores tocando, mas profissionais não se envolviam”. Entre 1949 e 1956, Price desenvolveu o primeiro grupo de percussão universitário registrado e criou espaço para os estudantes se especializarem e performar o repertório escrito até então, com as obras de Cowell, Varese, Roldan, Harrison, Cage, Antheil, entre outros ${ }^{14}$.

No Brasil os primeiros grupos começaram a surgir nos anos de 1960, a saber, o Conjunto de Percussão da UFBA (1964) e o Grupo de Percussão de São Paulo (1967), em ambos casos esses grupos não se reuniam de maneira fixa e não eram formalmente constituídos, se reuniam para execução de obras específicas. O Grupo de Percussão de São Paulo era formado por percussionistas profissionais, enquanto o Conjunto de Percussão da UFBA era integrado por músicos de diversas áreas, como veremos mais adiante (TULLIO e SULPICIO, 2016, p. 8).

Esses conjuntos são considerados uma novidade, pois se constituem como uma nova modalidade de música de câmara, abrindo o campo para novas composiçóes escritas somente para percussão. Não existe um número definido de instrumentistas que compõem esses grupos, que pode variar de três a todos aqueles que são desejados pelo compositor. Estudio en forma de preludio y fuga, composta em 1933 por José Ardévol, por exemplo, é pensada para 22 percussionistas que tocam 37 instrumentos. Diversamente, a peça Trio, for three percussion players, escrita em 1936 por John Cage, é concebida para três instrumentistas que tocam 16 instrumentos.

Nas peças para grupo de percussão, cada músico pode tocar um só instrumento ou vários, organizados como unidade, em forma de "percussão múltipla" ${ }^{15}$. Outra variável na formação desses grupos diz respeito aos tipos de instrumentos utilizados, pois nem sempre o compositor explicita quais são. Existem muitos exemplos em que a escolha do timbre a ser utilizado é voluntariamente deixada para o instrumentista. Um dos primeiros exemplos dessa liberdade de escolha é Quartet for percussion: no instrument specified (1935) composta por John Cage.

\footnotetext{
${ }^{14}$ Disponível em https://www.pas.org/about/hall-of-fame/paul-price. Acesso em: 20 abr. 2021.

${ }^{15}$ Para Schick (2006, apud TULLIO e SULPICIO, 2016, p. 2) "um instrumento de percussão múltipla consiste em uma série de instrumentos individuais arranjados de tal maneira que um percussionista possa tocar todos como uma "unidade poli instrumental singular".
} 
As primeiras composições reconhecidas para Grupo de Percussão são as Ritmica No 5 e Rítmica No 6, escritas em 1930, pelo compositor cubano Amadeo Roldán. Elas fazem uso de tímpanos, bumbos sinfônicos e outros instrumentos de origem indígena. Rítmica No 5 foi escrita para 11 percussionistas que tocam 13 instrumentos e Ritmica No 6 para 11 percussionistas que tocam 11 instrumentos. Outra obra reconhecida por ser pioneira nesse gênero é Ionisation de Edgar Varèse, de 1931, escrita para 13 percussionistas e 37 instrumentos, entre eles um pianoforte.

Após a Segunda Guerra Mundial, a produção de composições para grupo de percussão foi menos intensa. Para Parker (2010), as escolas de música tiveram um papel predominante para uma segunda fase de desenvolvimento dos grupos de percussão. "No ano de 1950, essa formação foi incorporada ao programa curricular da Universidade de Illinois pelo percussionista e professor Paul Price, gerando interesse por parte de outros pedagogos que também o incorporaram no currículo de outras escolas norte-americanas.” (PARKER apud TULLIO e SULPICIO, 2016, p. 6).

No Brasil, a primeira peça para grupo de percussão é atribuída a Camargo Guarnieri, Estudo para Instrumentos a Percussã $0^{16}$, para 8 percussionistas, de 1953, sendo executada somente em 1979 (BOUDLER, 1983, p. 2).

Estudo para Instrumentos de Percussão [sic.] de Camargo Guarnieri, de 1953, é considerada como sendo a primeira peça escrita no Brasil para Grupo de Percussão. De acordo com Hashimoto (2003, p.70), essa peça só foi publicada em 1974 e a sua estreia se deu em 07 de novembro de 1979, na Fundação das Arte de São Caetano do Sul, com o Grupo Percussão Agora. (TULLIO e SULPÍCIO, 2016, p. 6).

As primeiras obras a serem executadas no Brasil foram Ritual e Transe (1964) para 7 percussionistas de Jamary Oliveira, Três Estudos para Percussão (1966) de Osvaldo Lacerda e Rhythmetron (1968) para 10 percussionistas de Marlos Nobre (ARILHO e HASHIMOTO, 2014).

As universidades brasileiras tiveram um papel muito importante na criação de grupos de percussão. O primeiro foi o Conjunto de Percussão da UFBA, criado em 1964, e o segundo foi o

\footnotetext{
${ }^{16}$ Gianesella (2012) realiza um estudo sobre problemas de nomenclatura e tradução em peças de Camargo Guarnieri e outros compositores, nele relata que no manuscrito de Guarnieri o título dessa peça se encontra com essa grafia Estudo para Instrumentos a Percussão e que a instrumentação está escrita em italiano. Em gravações, estudos e transcrições posteriores não é raro encontrar referência a essa obra como sendo Estudo para Instrumentos de Percussão. Nesse artigo optamos por adotar o nome original do manuscrito. Sugerimos assistir a obra nesta performance do Grupo de Percussão da UFRJ (2014). Disponível em: https://www.youtube.com/watch?v=aliUEXp48no. Acesso em: 07 jan. 2021.
} 
Grupo de Percussão de São Paulo, de 1967. Os dois eram integrados por músicos que não eram percussionistas profissionais e não tinham uma regularidade em seus encontros, mas foram pioneiros nas apresentações de música brasileira escrita para percussão, com execuções de composições de Jamary Oliveira, Milton Gomes, Osvaldo Lacerda, entre outros. Julgamos relevante nos debruçarmos na próxima seção, sobre o primeiro grupo brasileiro, o Conjunto de Percussão da UFBA, exemplificando compositores e obras importantes do repertório de percussão contemporânea.

\section{3 - Conjunto de Percussão da UFBA - alguns personagens e obras relevantes}

"Na década de 1960, a compositora brasileira Jocy de Oliveira e o maestro Eleazar de Carvalho tiveram fundamental importância para a inserção da música contemporânea no Brasil, ao realizarem as duas Semanas de Música de Vanguarda, respectivamente, em 1961 e 1966.” (TULLIO, 2014, p. 55). O Conjunto de Percussão da UFBA ${ }^{17}$, formado em 1964, "foi o primeiro grupo do gênero a surgir no Brasil” (TULLIO, 2014, p. 71) e foi fruto da iniciativa de alunos de composição dos Seminários de Música da UFBA. Falaremos aqui de três de alunos (Jamary Oliveira, Lindembergue Cardoso e Fernando Cerqueira) que escreveram obras relevantes para o desenvolvimento do repertório contemporâneo percussivo brasileiro, estimulando explorações e inovaçóes para a família dos instrumentos de percussão. Esses alunos foram da turma do professor Ernst Widmer.

O grupo foi criado a partir da iniciativa dos alunos Fernando Cerqueira e Rinaldo Rossi, com o objetivo de estudar música afro baiana e aprender a tocar alguns instrumentos de percussão, como o berimbau e atabaques. Por conta dessa ideia, alguns alunos se reuniram e organizaram alguns concertos. Vale aqui ressaltar o primeiro desses concertos, que aconteceu no dia 9 de julho de 1964, na Reitoria da UFBA, onde estrearam as obras Ritual e Transe (1964) de Jamary Oliveira e Estrutura (1964) de Milton Gomes, ambas compostas no mesmo ano (TULLIO, 2014), além de outras obras para outras formaçôes de grupo de câmara.

Segundo Tullio (2014), o grupo era formado por compositores que tocavam e regiam as obras. Na FIGURA 1 podemos observar a sua formação original.

\footnotetext{
${ }^{17}$ Para maiores informações, ver Tullio (2014) e Tullio e Sulpício (2016), dentre outros.
} 
FIGURA 1 - Ex-integrantes do Conjunto de Percussão da UFBA, reunidos na Escola de Música, em Salvador (1970). $\mathrm{Na}$ foto da direita para esquerda: Jamary Oliveira, Lindembergue Cardoso, Rufo Herrera, Ernst Widmer, Milton Gomes, Walter Smetak, Lucemar Alcântara Ferreira.



Fonte: Disponível em: http://www.mhccufba.ufba.br/SISMHCC/mhcc_index.php?idioma=pt\&secao=6 Acesso em 20 abr. 2020.

Segundo Tullio (2014), a primeira obra a ser composta e executada, em 1964, foi Ritual e Transe (1964) de Jamary Oliveira, como exibiremos mais à frente.

Em 1968, outro concerto aconteceu em Salvador. O Conjunto de Percussão da UFBA, no Teatro Castro Alves, sob a regência de Ernst Huber Contwig, estreou peças como Conjunto II de Jamary Oliveira, Caricaturas (1968) de Lindembergue Cardoso (obra que também abordaremos em breve), entre outras obras (TULLIO, 2014).

A Escola de Música da UFBA, até os dias atuais, é uma instituição de muita relevância para o cenário da música contemporânea no Brasil. O Conjunto de Percussão da UFBA encerrou suas atividades em 1968, entrando em cena o atual Grupo de Percussão da UFBA a partir de 1995, coordenado pelo professor Dr. Jorge Sacramento (ALMEIDA, 2021). 
Em entrevista concedida pelo professor Sacramento (ALMEIDA, 2021), ele comentou: "o grupo retornou às atividades em 1995, com um aluno, Gilberto Santiago. [...] Nesse mesmo ano teve o primeiro concerto do Grupo de Percussão da UFBA, no segundo semestre de 1995”.

A característica principal do referido grupo, desde o seu surgimento, é a execução de obras de compositores da própria instituição, que trazem em suas escritas influências da cultura afro-baiana, objeto de pesquisa de boa parte dos alunos do curso de percussão. Sobre isso, o professor Sacramento (ALMEIDA, 2021) comenta que depois de inventar os projetos Compositores Baianos Vivos e o Festival da Interação, com os alunos de composição do professor Wellington Gomes, o grupo começou a crescer na música escrita contemporânea. Depois disso, o grupo participou de projetos como Tributo a Pixinguinha, Tributo a Waldir Azevedo, Tributo a Dodô e Osmar, Repercutindo na Comunidade, Sonora Brasil e o Festival de Percussão 2 de Julho, que completou dez ediçóes em 2019.

Atualmente, o curso e o grupo são coordenados pelos professores Dr. Jorge Sacramento e Me. Aquim Sacramento (FIGURA 2).

FIGURA 2 - Foto do Grupo de Percussão da UFBA (2019). Da esquerda para direita: Jorge Sacramento (coordenador), Aquim Sacramento (coordenador), Carlos Blanco (convidado), Edwã Victor, Rian Mourthé, João Victor Melo, Isaac Falcão (convidado) e Josué Rodrigues.

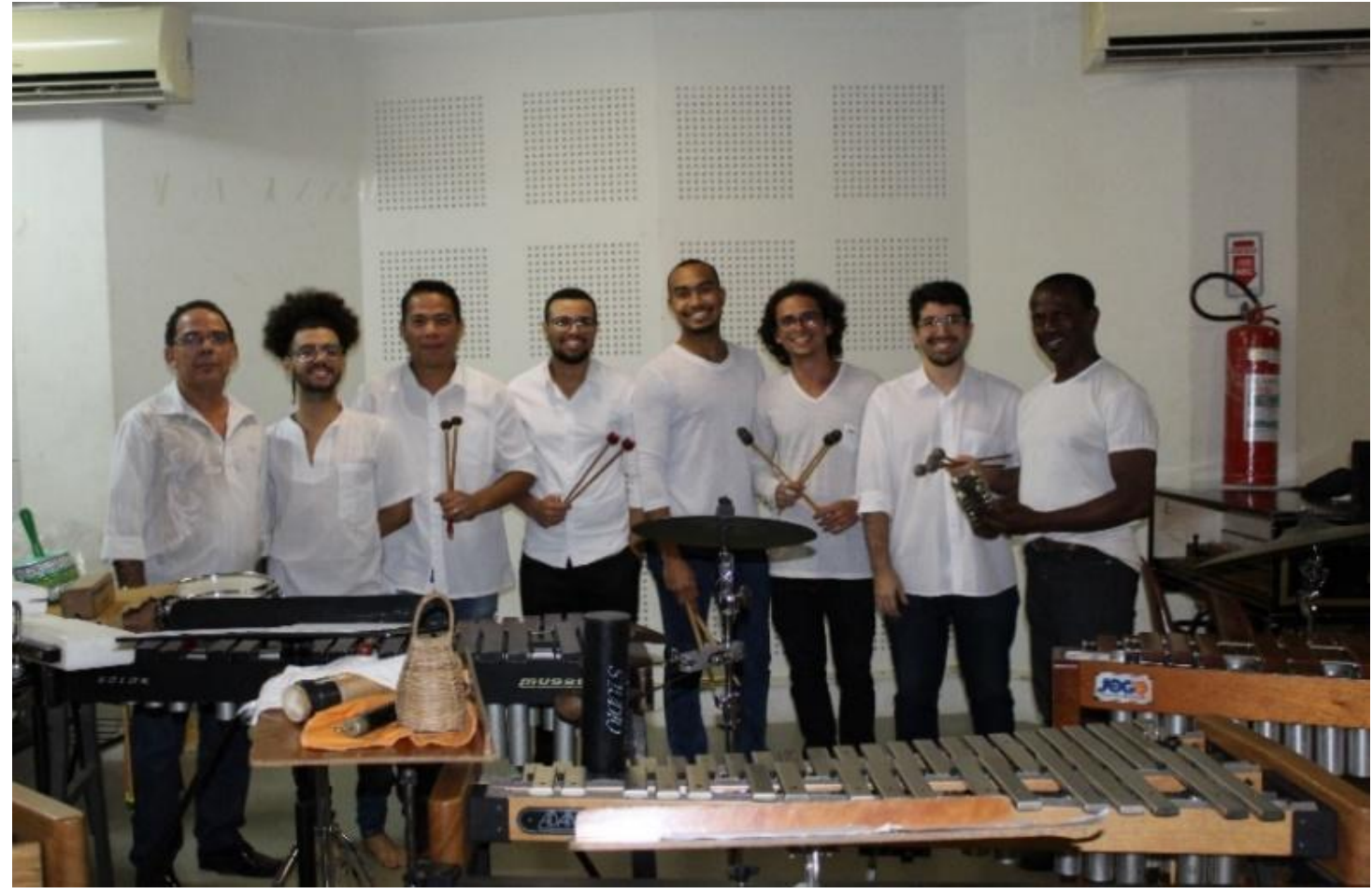

Fonte: Acervo pessoal do autor. 
A Escola de Música da UFBA, sendo uma instituição com renomada tradição na música escrita ocidental, continuou sendo um importante celeiro para grandes compositores e as suas composições, escritas para percussão em diferentes formações e para outros instrumentos. Novas técnicas e novas ideias de timbre e sonoridade, unidas a conexão entre percussão e voz, foram postas, como na obra de Fernando Cerqueira, Expressóes Cibernéticas (1985), que utiliza instrumentos como o flexatone, garrafas de vidro (para soprar), matraca, folha de zinco, dentre outros. Essa obra, como veremos mais à frente, foi escrita para cinco percussionistas e um cantor (soprano ou tenor).

A seguir, abordaremos três obras: Ritual e Transe (1964) (Jamary Oliveira), Caricaturas (1968) (Lindembergue Cardoso) e Expressóes Cibernéticas (1985) (Fernando Cerqueira). A escolha dessas três obras se deu pela importância que os três compositores tiveram junto ao Grupo de Percussão da UFBA, pioneiro do gênero no Brasil, sendo que as duas primeiras obras citadas têm grande importância histórica, pois Ritual e Transe, de Jamary Oliveira é a primeira obra para percussão executada no Brasil, e Caricaturas, de Lindembergue Cardoso também está entre as primeiras obras para percussão compostas e executadas no Brasil por compositores integrantes do Grupo de Percussão da UFBA em sua primeira fase (1964-68). Já Expressóes Cibernéticas foi escrita em 1985 por Fernando Cerqueira, que também integrou o Grupo de Percussão da UFBA nos anos 60, e serve de parâmetro para mostrar a evolução da escrita da percussão ao longo desses 20 anos.

Além disso, apresentaremos um breve panorama desses compositores, suas obras e suas principais características, além de apontar elementos que percebemos serem tradicionais no repertório contemporâneo percussivo baiano das épocas tratadas.

\section{1 - Ritual e Transe (Jamary Oliveira) - 1964}

O compositor e professor Jamary Oliveira (1944-2020), nasceu na cidade de Saúde, na Bahia. Em 2020, o músico faleceu deixando um legado importantíssimo como membro da Academia Brasileira de Música, da Associação Brasileira de Educação Musical, membro fundador do Grupo de Compositores da Bahia, como mencionado anteriormente ${ }^{18}$, dentre outros cargos. O professor

\footnotetext{
${ }^{18}$ Informação retirada do Site da UFBA. Disponível em: https://ufba.br/ufba_em_pauta/nota-de-pesar-jamaryoliveira. Acesso em: 08 jan. 2021.
} 
Jamary concluiu a graduação em Educação Musical em 1966, e a de Composição em 1969, na turma do respeitado Ernst Widmer"19. "Personagem fundamental na história da Escola, Jamary colaborou na formação de várias geraçôes de alunos” (Site da UFBA) ${ }^{20}$.

Oliveira, um dos principais precursores do Conjunto de Percussão da UFBA, foi o compositor que, acompanhado do seu interesse de aprender ritmos e instrumentos afro-baianos, impulsionou o repertório percussivo contemporâneo da Bahia, compondo a primeira obra para o grupo de percussão, escrita e estreada no ano de 1964.

Ritual e Transe ${ }^{21}$ (1964), diferente das duas próximas obras que abordaremos, não se utiliza da voz, porém, entendemos que a sua relevância, por ter sido a primeira obra brasileira para grupo de percussão executada no país, é significativa a ponto de citarmos e exemplificarmos com alguns apontamentos aqui neste trabalho.

Essa obra contém dois movimentos e tem como características principais a utilização de instrumentos afro-baianos como atabaques, agogô, reco-reco, mas também requer instrumentos da percussão orquestral como tímpanos e triângulo. Sua partitura, segundo Tullio (2014), tem notação tradicional e conta com compassos simples, mas com diferença de andamentos entre um movimento e outro, como veremos no trecho recortado na FIGURA 3:

\footnotetext{
${ }^{19}$ Informação retirada do Site da Academia Brasileira de Música. Disponível em: http://www.abmusica.org.br/academico/\%E2\%80\%8Bjamary-oliveira/. Acesso em 07 de jan. de 2021. ${ }^{20}$ Informação retirada do Site da UFBA. Disponível em: https://ufba.br/ufba_em_pauta/nota-de-pesar-jamaryoliveira. Acesso em: 08 jan. 2021.

${ }^{21}$ Sugerimos ouvir a obra no CD Ouça Sfot Poc do Grupo de Percussão da UFBA (2019). Disponível em: https://www.youtube.com/watch?v=V4ptWm3JTfk\&list=OLAK5uy_nSdbwjVWjtPj2q6pCdbYowoL2EEYMM540. Acesso em: 07 jan. 2021.
} 
FIGURA 3 - Página 12 da obra Ritual e Transe (1964) de Jamary Oliveira, que requer sete percussionistas.
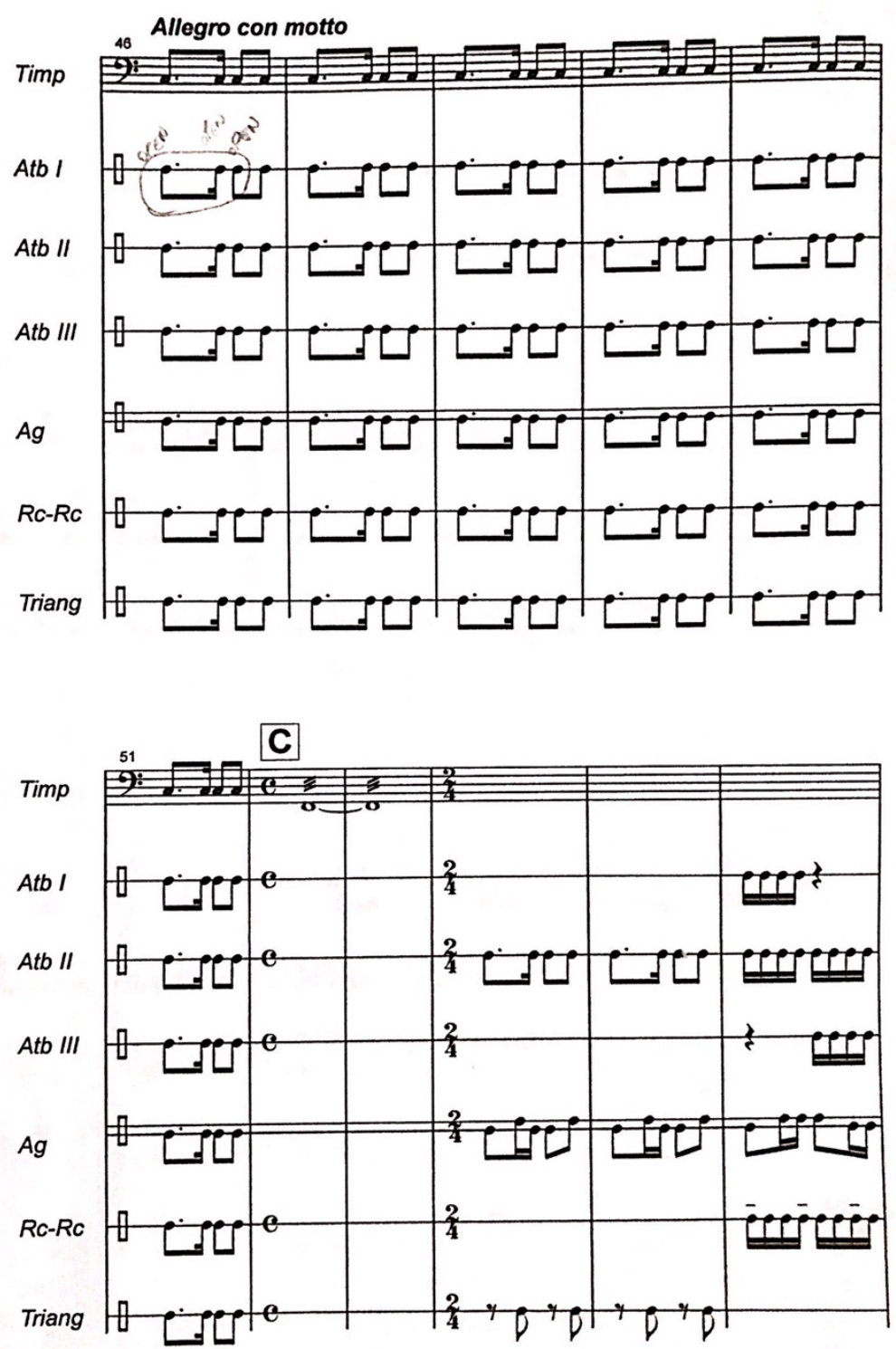

Fonte: Acervo do Núcleo de Percussão da UFBA.

O trecho acima aponta uma mudança de andamento, no segundo movimento, compasso 46; e exibe uma mudança de compasso, de $2 / 4$ para 4/4, e novamente para 2/4. Além disso, os ritmos se mostram complementares e simples, características observadas nas obras brasileiras daquela época.

A partir desse pontapé inicial, os compositores, até os dias atuais, mergulham na tradição afrobaiana para criar suas obras. Do berimbau à marimba; da tonalidade à atonalidade; do rítmico ao aleatório. Características como essas são importantíssimas e muito presentes no repertório percussivo dos alunos de composição da instituição, até hoje. 


\section{2 - Caricaturas (Lindembergue Cardoso) - 1968}

Em 1968, no segundo concerto do Conjunto de Percussão da UFBA, executado no Teatro Castro Alves, foram estreadas diversas obras para diversas formações instrumentais (CARDOSO, 1968). Uma delas é a do professor Lindembergue Cardoso (1939-1989) que compôs Caricaturas (1968) para grupo de percussão (PÉREZ, 2009, p.82). Cardoso nasceu em Livramento de Nossa Senhora, em 1939, mas se inseriu nos ambientes da escola de música apenas em 1958, quando ingressou nos antigos Seminários de Música. No entanto, foi em 1962 que iniciou seu trajeto no Madrigal (o coro de câmara em atividade até os dias atuais) e em 1964 se torna Professor de Música em Salvador. Em 1967, o professor Ernst Widmer encomendou, aos alunos de composição, pequenas obras para coro (PÉREZ ,2009; CARDOSO, 1994). Os alunos eram escolhidos por Widmer e nessa mesma turma contava com nomes como Jamary Oliveira e Fernando Cerqueira, autores também abordados neste artigo.

Entre 1967 e 1968, Lindembergue Cardoso escreveu, dentre outras obras, Caricaturas ${ }^{22}$ (1968) para conjunto de percussão, onde recorre a citações de peças de Bach, Mozart e Mendelssohn. A obra requer oito percussionistas, contando com os instrumentos da percussão orquestral (os que comumente estão presentes na orquestra sinfônica), como o bombo, o triângulo, a caixa-clara, o tímpano (que ele especifica ser com pedal) e o xilofone, mas também percebemos os bongôs, o recoreco, o agogô, o vibrafone, o prato suspenso, o bloco de madeira (que ele apenas chama de madeira) e o guizo. A maioria destes instrumentos eram bastante utilizados nas primeiras obras para percussão, percebendo a união entre os instrumentos clássicos com os da cultura popular ou tradicional.

O compositor trabalha com a escrita tradicional para percussão e utiliza os instrumentos de maneira tradicional, trabalhando com glissandos e baquetas diferentes. Como uma das características das obras da década de 1960, a improvisação a partir do direcionamento dado pelo autor está presente, como podemos ver na FIGURA 4:

\footnotetext{
${ }^{22}$ Sugerimos assistir a performance da obra pelo Grupo de Percussão da UFBA (2007). Disponível em: https://youtu.be/i-krJUhalbg. Acesso em: 07 jan. 2021.
} 
FIGURA 4 - Última página da obra Caricaturas (1968) onde indica o momento de improvisação para 6 dos 8 instrumentistas requeridos pelo compositor.

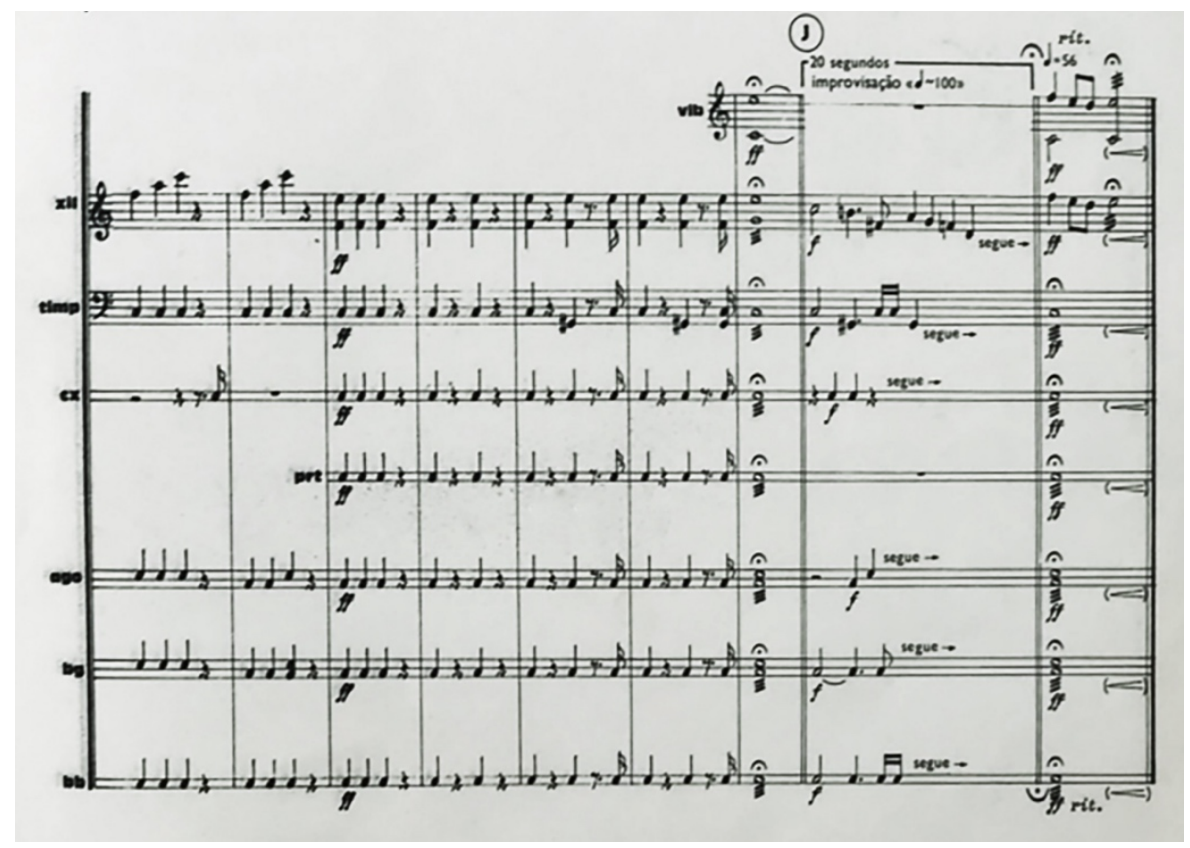

Fonte: Acervo do Núcleo de Percussão da UFBA.

Além de explorar estes instrumentos, ele se utiliza da voz, um dos objetos da nossa pesquisa, através do assobio, reproduzindo um trecho da famosa Marcha Nupcial, de Mendelssohn, como podemos perceber na FIGURA 5.

FIGURA 5 - Página 7 da obra Caricaturas (1968) onde indica o momento do assobio na obra.

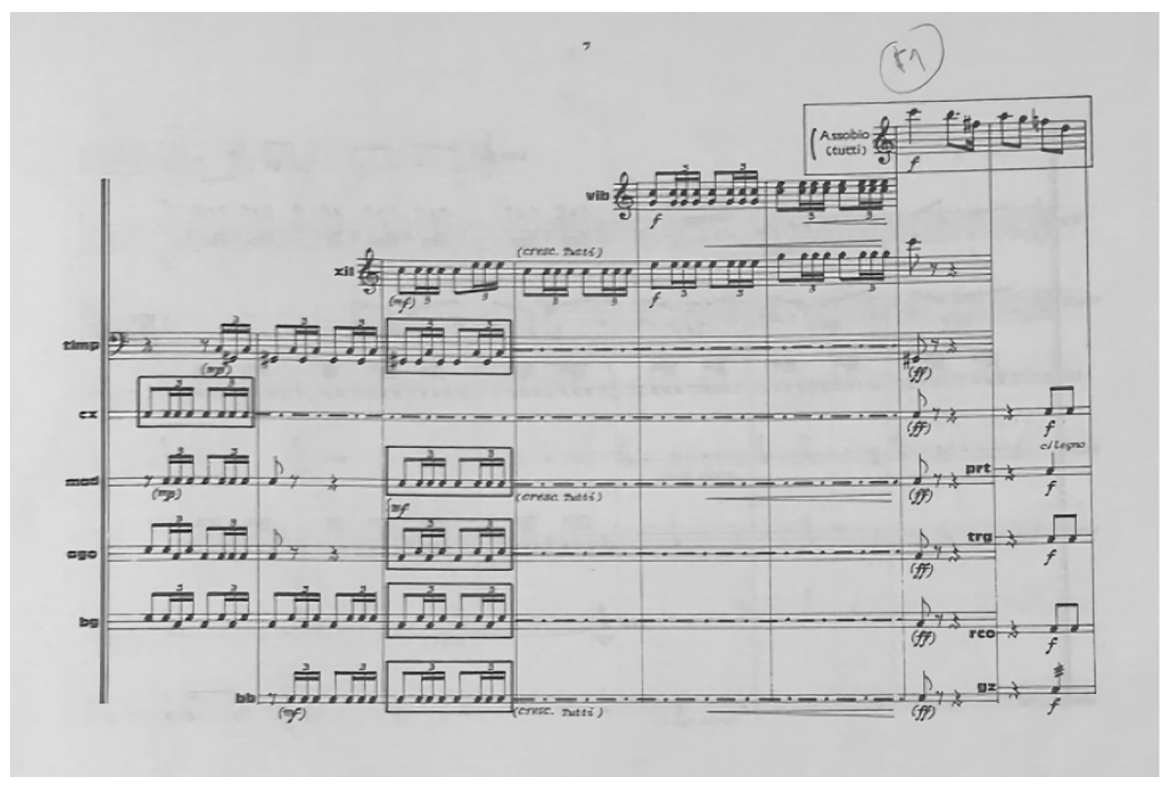

Fonte: Acervo do Núcleo de Percussão da UFBA. 
Nas décadas seguintes os compositores pioneiros integrantes deste importante grupo de percussão continuaram escrevendo para esse tipo de formação, assim como para outros instrumentos. Foram décadas de muitas produções, tanto pela geração da década de 1960, quanto pelas seguintes.

\section{3 - Expressôes Cibernéticas (Fernando Cerqueira) - 1985}

O compositor e educador-pesquisador Fernando Cerqueira, também clarinetista e cantor, se formou integralmente na Escola de Música da UFBA, sendo um dos talentosos alunos de Widmer (na mesma turma de Cardoso e Oliveira), entre outros professores, se formando em $1969^{23}$. Apenas no ano seguinte iniciou sua carreira docente no Departamento de Música em Brasília lecionando diversas disciplinas. Em 1975 retornou a Salvador ingressando no corpo docente da Escola de Música da UFBA, se aposentando apenas em 1994.

No entanto, em 1966, um período antes de Brasília, fundou o Grupo de Compositores da Bahia, grupo esse que foi de extrema relevância para o desenvolvimento do repertório percussivo. Suas obras se inspiravam em temas folclóricos nordestinos, motivos indígenas e também na literatura poética brasileira, como na obra: Expressóes Cibernéticas (1985), que, segundo ele em seu próprio texto/bula da obra:

\footnotetext{
Visa atingir indireta e criticamente as relações no campo da cibernética, utilizando metáforas contidas nos poemas de Lewis Carroll, Haroldo de Campos e Paulo Leminski, para expor analogias entre máquinas, animais e a realidade humana. Olhando através da fechadura do óbvio, o texto poético, enquadrado e ampliado pelo contexto acústico musical, denunciará ao ouvinte atento o falso naturalismo dos mecanismos, da massificação, da violência, da mitificação. (Texto da bula, 1985).
}

A obra se utiliza dos textos: Magma (fragmento de De signantia: quasi coelum) de Haroldo de Campos; A máquina de Paulo Leminski; Poema-cauda de Lewis Carroll (trad. de H. de Campos); e Serpentário de P. Leminski. Anterior à partitura, ele apresenta um gráfico (FIGURA 6) que contêm as palavras desses textos:

\footnotetext{
${ }^{23}$ Informação retirada do Site da UFBA. Disponível em: http://www.mhccufba.ufba.br/SISMHCC/mhcc index.php?idioma=pt\&secao=3\&extra=5. Acesso em: 08 jan. 2021.
} 
FIGURA 6 - Gráfico construído pelo autor com exibição dos textos requeridos na obra Expressões Cibernéticas (1985).

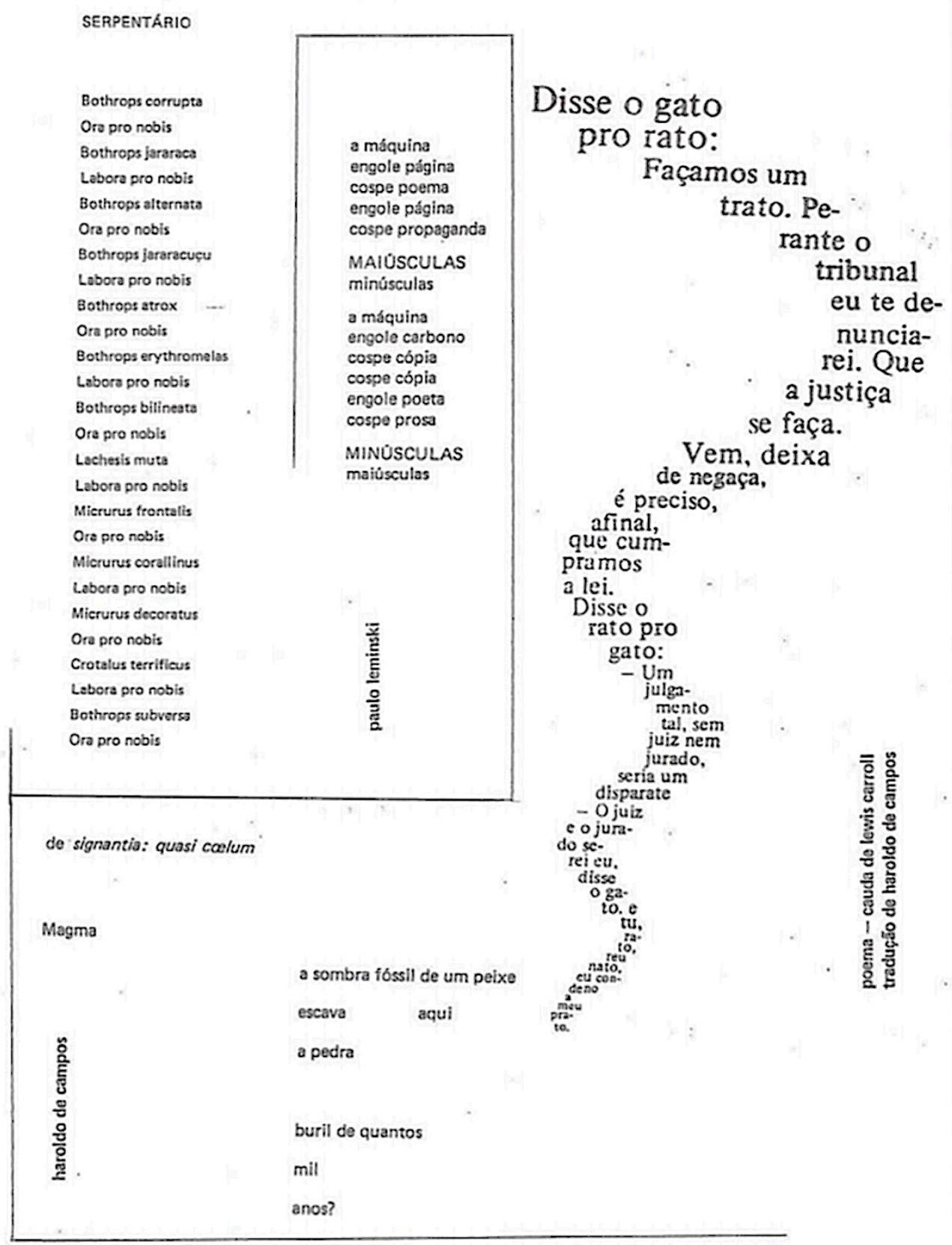

Fonte: Acervo do Núcleo de Percussão da UFBA.

A obra foi composta em 1985 e foi estrada no mesmo ano, na Bienal de Música Brasileira Contemporânea na Sala Cecília Meireles no Rio de Janeiro pelo Grupo PIAP24, dirigido por John

\footnotetext{
${ }^{24}$ O Grupo PIAP (Grupo de Percussão do Instituto de Artes da UNESP) foi criado e dirigido pelo americano John
} 
Boudler, com a participação da soprano Carol McDavit. A composição requeria um grupo de percussão com cinco integrantes e um cantor(a) - soprano ou tenor. Os percussionistas também precisavam falar trechos do texto exibido na imagem anterior (FIGURA 6).

Dentre os momentos de utilização da voz do cantor, o compositor pede que por diversos momentos a voz seja falada, ao invés de cantada, pelo cantor ou cantora. Além disso, palavras em português e em latim são misturadas nos diversos contextos e seçôes da música. Uma outra característica da obra pode ser percebida através do diálogo travado entre a voz e os instrumentos de percussão, mostrando-os de maneira canônica, repetitiva ou complementar.

Em duas seçóes, os percussionistas, por sua vez, precisam dialogar com o(a) cantor(a) através de trechos do texto, falando versos de resposta ou até versos complementares ao do cantor. Isso, claro, com mudanças de dinâmica, andamento e instrumentos, na medida em que a obra se desenvolve, até a retomada do tema inicial. Na FIGURA 7 podemos perceber esse diálogo: 
FIGURA 7 - Compassos 189 ao 193 da obra Expressóes Cibernéticas (1985) onde podemos perceber a linha do canto/cantora e também as linhas de percussão e da voz de cada percussionista.

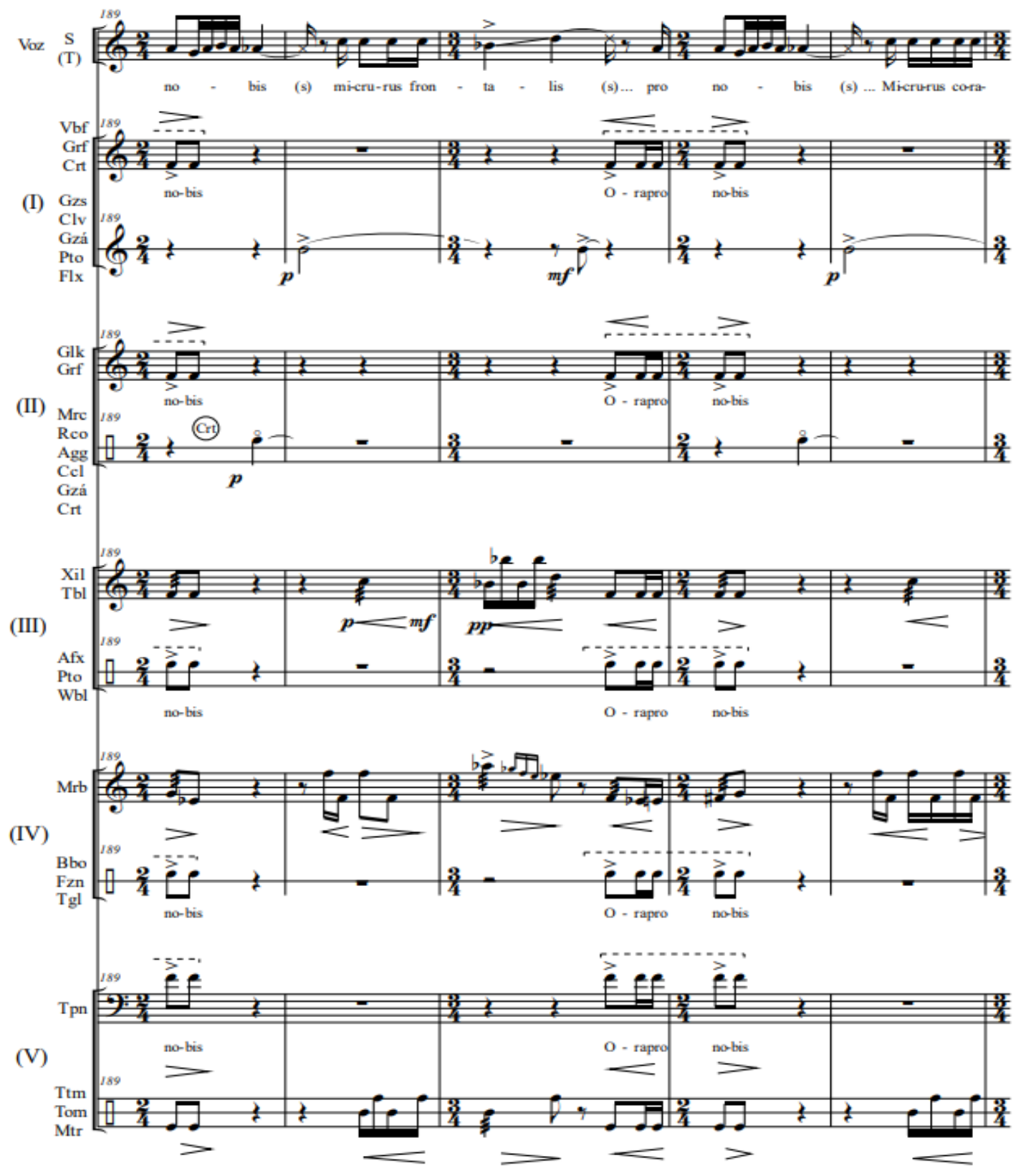

Fonte: Acervo do Núcleo de Percussão da UFBA.

Em 1986, o Grupo PIAP fez a primeira gravação da obra, no LP Compositores da Babia 7, com a participação da cantora Marta Herr. Posteriormente essa gravação foi remasterizada e também está disponível no CD 86 do mesmo grupo, lançado no ano de 2004. Entre 2018 e 2019, a obra foi gravada pelo Grupo de Percussão da UFBA, no CD Ouça Sfot Poc, dirigido e produzido por Jorge Sacramento (coordenador deste mesmo grupo), com direção musical (nesta obra em específico) do próprio 
compositor. Esta gravação pode ser ouvida, dentre outras plataformas, no YouTube ${ }^{25}$. O lançamento deste CD, que foi realizado no X Festival de Percussão 2 de Julho, em 2019, contou com a execução desta mesma obra, com a regência do maestro e professor José Maurício e cantada pela cantora Marilda Costa. Esta performance pode ser vista também no YouTube ${ }^{26}$.

Segundo Tullio (2014), desde os anos de 1960 até hoje, podemos observar quatro fases de evolução dos Grupos de Percussão no Brasil: a primeira marcada pela criação dos grupos universitários (1964 a 1972); a segunda com a criação do Grupo de Percussão do Conservatório Musical Brooklin Paulista e com a chegada do percussionista norte americano John Boudler (1973 a 1977); a terceira caracterizada pela atuação dos grupos PIAP e Percussão Agora (1978 a 2000); e a quarta fase que vê a criação de uma grande quantidade de novos grupos (2000 aos dias atuais).

\section{4 - Reflexões em forma de conclusão}

O repertório escrito para percussão iniciado a partir dos anos de 1930 é um campo de experimentação muito variado, seja do ponto de vista da produção do som, da organologia, da performance dos músicos. Além de experimentaçóes rítmicas e tímbricas podemos perceber uma exploração da utilização da voz em obras para percussão desde o século $\mathrm{XX}$, isso por que os movimentos estéticos surgiram com o intuito de trazer o novo através de sons e ruídos nunca dantes requeridos pelos compositores. Alguns desses sons foram citados nas categorias do Manifesto Futurista L'Arte dei Rumori, texto de Russolo que traz a voz sendo utilizada de diversas formas, característica essa percebida nas obras trazidas nesse trabalho. Essas obras devem ser consideradas como referenciais para o desenvolvimento do repertório de grupo de percussão contemporânea no Brasil, pois serviram de pontapé para compositores brasileiros escreverem obras para esta mesma formação.

\footnotetext{
${ }^{25}$ Sugerimos ouvir a gravação oficial do Grupo de Percussão da UFBA, no CD “Ouça Sfot Poc" (2019). Disponível em: https://www.youtube.com/watch?v=SKCGFjTqjNw\&list=OLAK5uy_kyFHK9AmmWHWp0AB17q-5-sWz56XjRwc. Acesso em: 07 jan. 2021.

${ }^{26}$ Acreditamos, para o leitor, ser interessante observar a performance da obra no lançamento do CD "Ouça Sfot Poc" do Grupo de Percussão da UFBA, no X Festival de Percussão 2 de Julho (2019). Disponível em: https://youtu.be/yd6xxLSbiD4. Acesso em: 07 jan. 2021.
} 
Algumas das características apresentadas nas peças podem ser vistas em composiçôes posteriores a elas. Em Ritual e Transe (1964), por exemplo, podemos perceber a utilização de instrumentos afro-religiosos, como o atabaque, agogô e instrumentos da cultura popular, como o reco-reco. Esses e outros instrumentos são utilizados em diversas peças, até hoje. Em Caricaturas (1968), podemos observar a utilização de citações de obras clássicas, mas de forma desordenada e atonal, misturado a utilização da voz, com o assobio. Além disso, percebemos momentos de improvisação guiada em um trecho da obra. Já em Expressões Cibernéticas (1985), podemos observar a presença do cantor, que explora a sua voz de forma cantada, murmurada, falada, entre outras formas. Além disso, os próprios percussionistas também utilizam a voz de forma complementar e/ou contrapontística se comparado ao cantor. Os instrumentos utilizados vão de instrumentos orquestrais (caixa, triângulo, bumbo, xilofone) a instrumentos da percussão popular (agogô, afoxé, reco-reco, ganzá, entre outros) e outros da percussão contemporânea (crotales, garrafa, flexatone, entre outros).

No cenário da música contemporânea esses autores e obras ainda servem de influência para os estudantes de composição e percussão no Brasil e no mundo.

\section{REFERÊNCIAS}

ALMEIDA, Aquim. Entrevista a Jorge Luís Sacramento de Almeida. Salvador, 14 de janeiro de 2021. Entrevista.

BARRETO, Jorge Lima. Percursos da percussão. Lisboa: Meloteca, 2009.

BOUDLER, John Edward. Brazilian percussion compositions since 1953: an annotated catalogue. Chicago, Illinois Estados Unidos. Tese (Doutorado em Música), American Conservatory of Music, 1983.

CARDOSO, Lindembergue. Caricaturas: para conjunto de percussão. Salvador: Centro Editoral e Didático UFBA, 1991. Partitura, p. 9, Grupo de Percussão.

CARDOSO, Lindembergue. Causos de Músico. Salvador, Bahia. Empresa Gráfica da Bahia, 1994.

CERQUEIRA, Fernando. Expressões Cibernéticas. Salvador: UFBA, 1985. Partitura, p.44. Grupo de Percussão.

CHARLE, Christophe. Fin de siècle. PLURAL, Revista do Programa de Pós-Graduação em Sociologia da USP, São Paulo, v.25.1, 2018, p.248-264. 
FACCHIN, Guido. Le percussioni: storia e tecnica esecutiva nella musica classica, contemporanea, etnica e d'avanguardia. Varese: Zecchini Editore, 2014.

GIANESELLA, Eduardo Flores. Percussão orquestral brasileira: problemas editoriais e interpretativos. São Paulo: UNESP, 2012.

HASIMOTO, Fernando Augusto de Almeida. Análise musical de "Estudo para instrumentos de percussão", 1953, M. Camargo Guarnieri; primeira peça escrita somente para instrumentos de percussão. Dissertação (Mestrado em Música), Instituto de Artes, Unicamp, Campinas, 2003.

HOBSBAWM, Eric J., Era dos Extremos: o breve século XX: 1914-1991. São Paulo: Companhia das Letras, 1995.

KLINGENDER, Francis Donald. Arte e rivoluzione industriale. Torino: Giulio Einaudi Editore, 1972.

MINARI, Aldo. Expo storia: unviaggio nel tempo. 1 dez. 2015. Disponível em:

https://issuu.com/brunomanuelalbano/docs/expo_storia._un_viaggio_nel_tempo). Acesso em: 20 jan. 2021.

OLIVEIRA, Jamary. Ritual e Transe. Salvador: UFBA, 1964. Partitura, p.13. Grupo de Percussão.

PÉREZ, Roberto Alejandro. Lindembergue Cardoso Técnicas e atitudes composicionais: o estudante e o compositor. Tese (Doutorado em Música e Musicologia), Departamento de Música, Évora, Portugal. 2009. Disponível em:

https://www.yumpu.com/pt/document/read/15722154/universidade-de-evora-lindemberguecardoso. Acesso em: 07 jan. 2021.

REMOTTO, Francesco. Contro natura: Una lettera al Papa. Bari: Gius, La Terza, e-book, 2014.

RUSSOLO, Luigi. L'arte dei rumori. Milano: Edizioni Futuriste di Poesia, 1916.

SANJAD, Nelson. Exposições internacionais: uma abordagem historiográfica a partir da América Latina. Hist. cienc. saude-Manguinhos, Rio de Janeiro, v.24, n.3, p.785-826, Sept. 2017. Disponível em http://www.scielo.br/scielo.php?script=sci arttext\&pid=S0104-

59702017000300785\&lng=en\&nrm=iso. Acesso em: 08 jan. 2021.

SCHAFER, R. Murray. A a finação do mundo: uma exploração pioneira pela história passada e pelo atual estado do mais negligenciado aspecto do nosso ambiente: a paisagem sonora. São Paulo: Editora UNESP, 2001.

Site da Academia Brasileira de Música. Disponível em: http://www.abmusica.org.br/academico/\%E2\%80\%8Bjamary-oliveira/. Acesso em: 08 jan. 2021.

Site da MHCC UFBA:

http://www.mhccufba.ufba.br/SISMHCC/mhcc_index.php?idioma=pt\&secao=3\&extra=5. Acesso em: 07 jan. 2021.

Site da UFBA. Disponível em: https://ufba.br/ufba_em_pauta/nota-de-pesar-jamary-oliveira. Acesso em: 08 jan. 2021.

TULLIO, Eduardo Fraga; SULPICIO, Eliana. Grupo de Percussão: breve histórico e primeiras performances no Brasil de 1964 a 1980. Revista Vórtex, Curitiba, v.4, n.3, 2016, p1-18. 
TULLIO, Eduardo Fraga. O Grupo do Brooklin - Semente da Percussão Contemporânea no Brasil. 2014, 234p. Tese (Doutorado em Música), Universidade de Aveiro, Portugal, 2014.

\section{REFERÊNCIAS DE VÍDEOS}

ABM, Academia Brasileira de Música. (2017). Camargo Guarnieri: Estudo para instrumentos de percussão / PROMUS / Grupo de percussão da UFRJ. Vídeo de 3 minutos e 30 segundos. Postado no YouTube por Academia Brasileira de Música ABM em 1 de dezembro, 2017. Disponível em: $<$ https://www.youtube.com/watch?v=aliUEXp48no $>$. Acesso em: 28 de jan. 2021.

DUSENBURY, Adele. (2017). "Ballet Mecanique"(Antheil) - Contemporary Chamber Players, Eduardo Leandro diretor. Vídeo de 17 minutos e 42 segundos. Postado no YouTube por Adele Dusenbury em 26 de maio, 2017. Disponível em: <https://www.youtube.com/watch?v=SWlQUlzh80w>. Acesso em: 28 de jan. 2021.

Grupo de Percussão da UFBA - Tema. (2017). Ritual e Transe. Vídeo de 4 minutos e 35 segundos. Postado no YouTube por Grupo de Percussão da UFBA - Tema em 1 de julho, 2017. Disponível em:

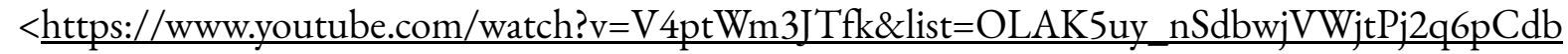
YowoL2EEYMM540>.Acesso em: 28 de jan. 2021.

Grupo de Percussão da UFBA - Tema. (2019). Expressóes Cibernéticas. Vídeo de 13 minutos e 54 segundos. Postado no YouTube por Grupo de Percussão da UFBA - Tema em 30 de julho, 2021. Disponível em:

<https://www.youtube.com/watch?v=SKCGFjTqjNw\&list=OLAK5uy kyFHK9AmmWHWp0 AB17q-5-sWz56-XjRwc>. Acesso em: 28 de jan. 2021.

Grupo de Percussão da UFBA. (2007). Caricaturas (Lindembergue Cardoso) - Grupo de Percussão da UFBA. Vídeo de 3 minutos e 46 segundos. Postado no YouTube por Grupo de Percussão da UFBA em 12 de janeiro, 2021. Disponível em: < https://youtu.be/i-krJUhalbg $>$. Acesso em: 28 de jan. 2021.

Grupo de Percussão da UFBA. (2019). Expressões Cibernéticas (Fernando Cerqueira) - regência de José Maurício/solista Marilda Costa. Vídeo de 13 minutos e 05 segundos. Postado no YouTube por Grupo de Percussão da UFBA em 12 de janeiro, 2021. Disponível em:

$<$ https://youtu.be/yd6xxLSbiD4 $>$. Acesso em: 28 de jan. 2021.

Ommalaga. (2016). Ballet Mécanique. 1924 - Canonical Version - Léger / Antheil. (Mechanical ballet). Synchro-Ciné. Vídeo de 15 minutos e 30 segundos. Postado no YouTube por Ommalaga em 27 de março, 2016. Disponível em: <https://www.youtube.com/watch?v=oWa2iy-0TEQ $>$. Acesso em: 28 de jan. 2021.

PLOUVIER, Jean-Luc. (2012). Ballet Mécanique (George Antheil)_Ictus Ensemble. Vídeo de 15 minutos e 28 segundos. Postado no YouTube por Jean-Luc Plouvier em 15 de abril, 2013. Disponível em: $<$ https://www.youtube.com/watch?v=FR9Qg7YVHaU $>$. Acesso em: 28 de jan. 2021. 


\section{SOBRE OS AUTORES}

Aquim Almeida é bacharel em Percussão pela UNESP, mestre em Educação Musical pela UFBA e doutorando em Performance Musical pela UFMG. Além disso, atua como professor de Percussão e coordenador do Núcleo de Percussão da Escola de Música da UFBA; possui trabalho solo executando concertos, ministrando palestras, masterclasses e oficinas no Brasil e em outros países, como a Colômbia e os EUA. ORCID: https://orcid.org/0000-0003-2699-7315. E-mail: aquimalmeida@hotmail.com

Cecilia Tamplenizza é doutora em Antropologia Cultural e Social da Università degli Studi di Milano-Bicocca em cotutela com o Programa Multidisciplinar em Cultura e Sociedade do IHAC da Universidade Federal da Bahia. Pesquisa performances corporais e musicais, rituais contemporâneos e suas interseçôes com as tecnologias. Atualmente é aluna do Curso de graduação em Canto da UFBA. ORCID: https://orcid.org/0000-0003-1292-262X. E-mail: ceciliatamplenizza@gmail.com 